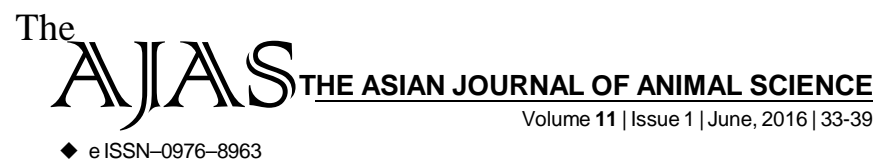

DOI : 10.15740/HAS/TAJAS/11.1/33-39 Visit us | www.researchjournal.co.in $\mathbf{S}$

\title{
Toxico-pathological studies on experimentally induced lead acetate toxicity in broiler chickens with protective effect of Opuntia elatior and Withania somnifera
}

\author{
T.M. SHAH, U.D. PATEL, V.R. NIMAVAT, D.T. FEFAR, V.A. KALARIA, B.B. JAVIA, H.H. SAVSANI AND \\ C.R. KOTADIYA
}

Author for Corresponding -

\section{T. M. SHAH}

Department of Pre-clinical and Safety Evaluation, Torrent

Research Centre - Bhat,

GANDHINAGAR (GUJARAT) INDIA Email:

mailto:urvesh1981@yahoo.com; Shahtrushenkumar@gmail.com

See end of the article for Coopted authors'

\begin{abstract}
The present study was carried out to evaluate the toxico-pathological manifestation of lead acetate toxicity in broiler chickens with protective effect of Opuntia elatior fruit juice and extract of Withania somnifera. Lead acetate was administered at dose rate of $500 \mathrm{ppm}$ in feed, P.O. for 21 days while Opuntia elatior fruit juice $(3 \mathrm{ml} / \mathrm{kg}$, P.O) and hydro-alcoholic extract of Withania somnifera $(100 \mathrm{mg} / \mathrm{kg})$ were administrated alone and in combination for consecutive 21 days in chickens of treatment groups. Symptoms of toxicity were observed after few days in chickens received only lead acetate. There was non-significant decrease in feed intake and body weight gain in birds of lead acetate treated group. Upon gross pathological examination, liver of birds from lead acetatetreatment group shown paleness, enlargement and fatty changes; whereas, kidneys shown haemorrhagic lesions and atrophy. Upon microscopic examination, liver of birds treated with lead acetate only showed varying degree of degenerative changes as well as vascular changes. Intestine of birds from lead treatment group showed denaturation and necrosis of tips of intestinal villi. No appreciable histopathological lesions were observed in the spleen and heart of birds in all treatment groups. In conclusion, administration of Opuntia elatior and Withania somnifera for longer period may improve performance of broilers chickens as well as act as protectant to organs.
\end{abstract}

KEY WORDS...... Opuntia elatior, Withania somnifera, Toxico-pathology, Lead acetate, Chickens

HOW TO CITE THIS ARTICLE - Shah, T.M., Patel, U.D., Nimavat, V. R., Fefar, D. T., Kalaria, V.A., Javia, B.B., Savsani, H.H. and Kotadiya, C.R. (2016). Toxico-pathological studies on experimentally induced lead acetate toxicity in broiler chickens with protective effect of Opuntia elatior and Withania somnifera. Asian J. Animal Sci., 11(1): 33-39 (DOI : 10.15740/HAS/TAJAS/11.1/33-39).

ARTICLE CHRONICLE - Received : 29.12.2015; Revised : 24.04.2016; Accepted : 18.05.2016 